\title{
Film models for transport phenomena with fog formation: the classical film model
}

\author{
H. J. H. BROUWERS \\ Akzo Research Laboratories Arnhem, Fibers Division, Department of Mcchanical Enginecring, \\ Velperweg 76, 6824 BM Arnhem, The Netherlands
}

and

\section{A. K. CHESTERS}

Eindhoven University of Technology, Faculty of Applied Physics, P.O. Box 513, 5600 MB Eindhoven, The Netherlands

(Received 29 August 1990)

\begin{abstract}
In the present analysis the classical film model (or film theory) is reviewed and extended. First, on the basis of a thorough analysis, the governing equations of diffusion, cnergy and momentum of a stagnant film are derived and solved. Subsequently, the well-known correction factors for the effect of suction/injection on mass, heat and momentum transfer are derived. Next, employing global balances of mass, energy and momentum, the film model is applied to channel flow. This application yields a new expression for the pressure drop and hence it is compared extensively with experimental and theoretical results of previous investigators, yielding good agreement. The onset of fog formation in a binary mixture, both in the transferring film and/or in the bulk, is explained graphically with the help of the relation between temperature and vapour mass fraction and the saturation line of the vapour.
\end{abstract}

\section{INTRODUCTION}

FOR LARGE mass transfer rates heat and diffusional mass transfer, as well as exerted friction, from a fluid to a wall are influenced by the extra flow due to the mass transfer (corresponding, effectively, to suction or injection). In the past corrections for this influence have been derived from three approximate theories or models-the boundary layer model, the penetration model, and the film model. Reviews of these models are found in Bird et al. [1] and Sherwood et al. [2].

The film model is physically the most simple description of the effect of the additional induced velocity, traditionally referred to as 'convective velocity', 'bulk velocity' or 'Stefan flow'. The model idealizes the transition between the fluid properties and those at the wall as occurring entirely within a thin film next to the wall. In this film, the influence of convection parallel to the wall is furthermore neglected. Though the correction factors supplied by the film model are based on a simple physical model, they are widely used in engineering applications, e.g. by Perry and Green [3] or V.D.I. [4]. This is due to the fact that the physical accuracy of the correction factors is generally sufficiently high for engineering end purposes, and they are easily applicable.

Stefan [5] was the first to study, experimentally and theoretically, the diffusional mass transfer in a stagnant film, including the induced velocity. Gilliland and Sherwood [6] and Colburn and Hougen [7] applied the film model to forced convective diffusional mass transfer. The latter authors also considered sensible heat transfer but overlooked the effect of the induced velocity on heat transfer. Ackermann [8] examined the effect of the induced velocity on both heat and mass transfer in a film. Colburn and Drew [9] did the same, and applied the film model to the case of closed channel flow. Mickley et al. [10] derived the three now well-known film model correction factors for mass, heat and momentum transfer, which can be applied to any process of importance. Additionally, they compared the predictions of the film model with those of the boundary layer model, performed experiments, and found satisfactory agreement. However, they did not consider the flow of a mixture through a confined space, such as a channel.

As a complete review of the film model-to the authors' knowledge-is absent, and in a following paper the model will be extended to include the effect of fog formation, the model is discussed in some detail here. The three film model correction factors are derived for a binary mixture, consisting of a vapour and inert gases. Subsequently, the correction factors are applied to the flow through a channel, resulting in expressions for the temperature and vapour mass fraction drop. Furthermore, on the basis of the film model correction factor for friction and an incremental momentum balance, a compact equation is derived predicting the pressure drop in a channel in the presence of the induced velocity. This equation, which is derived here in this form for the first time, will extensively be compared with results of several previous investigators. The formation of fog in a film and in a flowing mixture is visualized in a plot, depicting 


\section{NOMENCLATURE}

c vapour mass fraction

$c_{p} \quad$ specific heat $\left[\mathrm{J} \mathrm{kg}^{-1} \mathrm{~K}^{-1}\right]$

ID diffusion coefficient $\left[\mathrm{m}^{2} \mathrm{~s}^{-1}\right]$

$D_{\mathrm{h}} \quad$ hydraulic diameter; four times the crosssectional area divided by the perimeter of the channel [m]

$F \quad$ saturation line

$f$ friction coefficient

$G \quad$ relation between $c$ and $t$ in superheated region

$g_{m} \quad$ mass transfer coefficient $\left[\mathrm{kg} \mathrm{m}^{-2} \mathrm{~s}^{-1}\right]$

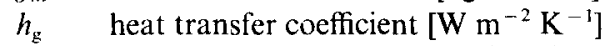

$k$ thermal conductivity $\left[\mathrm{W} \mathrm{m}{ }^{-1} \mathrm{~K}^{-1}\right.$ ]

Le Lewis number, $k / \rho c_{p} \mathbb{Q}$

$L e_{\mathrm{v}} \quad$ modified Lewis number, $k / \rho c_{p, \mathrm{v}} \mathbb{D}$

$\dot{m} \quad$ mass flux at wall $\left[\mathrm{kg} \mathrm{m}^{-2} \mathrm{~s}^{-1}\right]$

$\mathrm{Nu} \quad$ Nusselt number, $h_{\mathrm{g}} D_{\mathrm{h}} / k$

$n$ turbulent power-law coefficient

$q \quad$ heat flux at wall [ $\mathrm{W} \mathrm{m}^{-2}$ ]

$S c \quad$ Schmidt number, $\eta / \rho \mathbb{D}$

Sh Sherwood number, $g_{m} D_{\mathrm{h}} / \rho \mathbb{D}$

$t$ temperature [ $\mathrm{C}]$

$u$ component of velocity in the direction of $x\left[\mathrm{~m} \mathrm{~s}^{-1}\right]$ $v \quad$ component of velocity in the direction of $y\left[\mathrm{~m} \mathrm{~s}^{-1}\right]$

$x, y, z$ coordinates [m].

\section{Greek symbols}

$\delta \quad$ film thickness [m]

$\eta \quad$ dynamic viscosity [Pa s]

$\Theta$ correction factor

$\rho \quad$ density $\left[\mathrm{kg} \mathrm{m}^{-3}\right]$

$\tau \quad$ shear stress $\left[\mathrm{N} \mathrm{m}^{-2}\right]$

$\Upsilon$ time [s]

$\phi \quad$ dimensionless wall mass flux, defined by equations (20), (26) and (32).

$\begin{array}{cl}\text { Subscripts } \\ \mathrm{b} & \text { bulk } \\ c & \text { diffusional } \\ \mathrm{i} & \text { interface } \\ t & \text { thermal } \\ u & \text { frictional } \\ \mathrm{v} & \text { vapour. }\end{array}$

Superscript

- mean mixed or 'bulk'. the relation between temperature and vapour mass fraction in the film and path of the mean mixed values with respect to the saturation line.

As said, in this paper the film model of a binary mixture is studied. In the past the results of this model have also fruitfully been used to describe the transfer in multicomponent mixtures. The diffusion of each component is then analysed independently, thus considered as 'non-interactive', from all other components. However, Toor [11] examined for which exceptional circumstances diffusional interactions among the diffusing components become relevant. For these rare cases more complicated 'interactive' models are needed, see the comparative study of Webb and Sardesai [12]. The film model expressions based on the analysis of a binary mixture are then no longer accurate enough.

\section{THE FILM EQUATIONS AND THEIR SOLUTIONS}

In this section the equations describing heat, mass and momentum transfer in a film of a binary mixture, wherein there is an induced velocity caused by diffusion, are derived and solved analytically. The solutions are employed in the next section to define the film model correction factors.

\subsection{Mass transfer}

Consider a film containing non-condensable gases and a vapour, as depicted in Fig. 1, through which

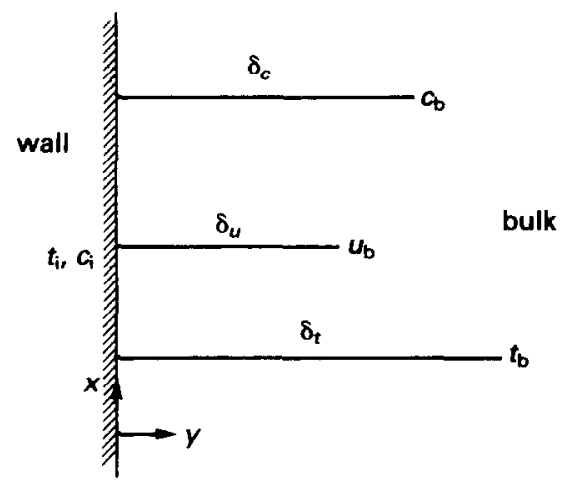

Fig. 1. The film.

there is a transfer of heat, mass and momentum in the $y$-direction, with flow parallel to the wall in the $x$ direction. At the 'wall' ( $y=0)$, e.g. denoting the surface of a liquid film, the vapour mass fraction is $c_{\mathrm{i}}$ and the temperature $t_{\mathrm{i}}$. At a distance $\delta_{c}$ the bulk vapour mass fraction, $c_{\mathrm{b}}$, is attained, at a distance $\delta_{t}$ the bulk temperature, $t_{\mathrm{b}}$, and at a distance $\delta_{u}$ the bulk velocity relative to the wall, $u_{\mathrm{b}}$. For the purposes of the present analysis the physical properties in the film are assumed to be constant and the mixture to behave as an ideal, incompressible, and Newtonian gas.

The full Fickian diffusion equation, e.g. see Merk [13], without source terms reads

$$
\rho\left(\frac{\partial c}{\partial \Upsilon}+u \frac{\partial c}{\partial x}+v \frac{\partial c}{\partial y}\right)=\rho \mathbb{D}\left(\frac{\partial^{2} c}{\partial x^{2}}+\frac{\partial^{2} c}{\partial y^{2}}\right) .
$$


Attention is restricted here to steady situations, for which therefore the first term, $\partial c / \partial \Upsilon$, is identically zero. In many cases the variation of $c$ (and $t$ and $u$ ) is small enough for the terms involving $\partial / \partial x$ to bc neglected as well; in this way the 'film model' is obtained, for which equation (1) reduces to

$$
\rho v \frac{\mathrm{d} c}{\mathrm{~d} y^{2}}=\rho \mathbb{D} \frac{\mathrm{d}^{2} c}{\mathrm{~d} y^{2}}
$$

In equation (2) the convective velocity $v$ is caused by diffusion of vapour through the mixture

$$
v=-\frac{\mathbb{D}}{1-c} \frac{\mathrm{d} c}{\mathrm{~d} y} .
$$

When this velocity is substituted into equation (2), an ordinary differential equation of $c$ in $y$ is obtained. The boundary conditions on $c$ read

$$
c(y=0)=c_{\mathrm{i}}
$$

and

$$
c\left(y=\delta_{c}\right)=c_{\mathrm{b}}
$$

Combining and solving equations (2) and (3), and applying boundary conditions (4) and (5), yields the distribution of the vapour fraction in the film as a function of $y$

$$
c(y)=1-\left(1-c_{\mathrm{i}}\right) \exp \left\{\frac{y}{\delta_{c}} \ln \left(\frac{1-c_{\mathrm{b}}}{1-c_{\mathrm{i}}}\right)\right\} .
$$

\subsection{Heat transfer}

In order to investigate the effect of the induced velocity on heat transfer, attention is now focused on the energy equation of the film. Again neglecting variations of $t$ in the $x$-direction, neglecting viscous dissipation, heat sources or radiation, for the film this equation reads

$$
\rho c_{p, v} v \frac{\mathrm{d} t}{\mathrm{~d} y}=k \frac{\mathrm{d}^{2} t}{\mathrm{~d} y^{2}}
$$

with as boundary conditions on $t$

$$
\begin{gathered}
t(y=0)=t_{\mathrm{i}} \\
t\left(y=\delta_{t}\right)=t_{\mathrm{b}} .
\end{gathered}
$$

Substitution of equations (3) and (6) into equation (7), solution of the resulting equation, and application of boundary conditions (8) and (9) now produces as temperature profile in the film

$$
t(y)=\left(t_{\mathrm{b}}-t_{\mathrm{i}}\right)\left[\frac{\exp \left\{\frac{y}{L e_{\mathrm{v}} \delta_{c}} \ln \left(\frac{1-c_{\mathrm{b}}}{1-c_{\mathrm{i}}}\right)\right\}-1}{\exp \left\{\frac{\delta_{t}}{L e_{\mathrm{v}} \delta_{c}} \ln \left(\frac{1-c_{\mathrm{b}}}{1-c_{\mathrm{i}}}\right)\right\}-1}\right]+t_{\mathrm{i}}
$$

where $L e_{\mathrm{v}}$ denotes the modified Lewis number.

\subsection{Momentum transfer}

To examine the influence of the induced velocity on the wall shear stress, the momentum equation for the $x$-direction is investigated. Again neglecting gradients of properties in the $x$-direction, as well as volume forces, this equation reads

$$
\rho v \frac{\mathrm{d} u}{\mathrm{~d} y}=\eta \frac{\mathrm{d}^{2} u}{\mathrm{~d} y^{2}}
$$

with appropriate boundary conditions on $u$ at the wall and bulk:

$$
\begin{gathered}
u(y=0)=0 \\
u\left(y=\delta_{u}\right)=u_{\mathrm{b}} .
\end{gathered}
$$

Substituting equations (3) and (6) in equation (11), solving the resulting equation and applying boundary conditions (12) and (13) results in

$$
u(y)=u_{\mathrm{b}}\left[\frac{\exp \left\{\frac{y}{S c \delta_{c}} \ln \left(\frac{1-c_{\mathrm{b}}}{1-c_{\mathrm{i}}}\right)\right\}-1}{\operatorname{cxp}\left\{\frac{\delta_{u}}{S c \delta_{c}} \ln \left(\frac{1-c_{\mathrm{b}}}{1-c_{\mathrm{i}}}\right)\right\}-1}\right] .
$$

In this equation the Schmidt number $S c$ has been introduced.

In this paragraph the vapour concentration, temperature and velocity profiles in the film have been derived, represented by equations (6), (10) and (14), respectively. On the basis of these solutions correction factors are arrived at in the next section.

\section{CORRECTION FACTORS FOR THE EFFECT OF THE INDUCED VELOCITY}

In this section the classical film model correction factors are introduced by comparing the transfer rates in the binary film with and without induced velocity.

\subsection{Mass transfer}

The mass transfer from the fluid to the wall is governed by Fick's law

$$
\dot{m} \equiv-\rho v(y=0)=\left.\frac{\rho \mathbb{D}}{1-c} \frac{\mathrm{d} c}{\mathrm{~d} y}\right|_{y=0} .
$$

Without taking account of the induced velocity, the mass transfer is simply described by

$$
\dot{m}=g_{m} \frac{c_{\mathrm{b}}-c_{\mathrm{i}}}{1-c_{\mathrm{i}}}
$$

because without induced velocity the profile of $c$ (and $t$ and $u$ ) as a function of $y$ is a straight line (the limiting cases of equations (6), (10) and (14) for small c). Equation (16) indicates that the mass flux is small for $c_{\mathrm{b}} \ll 1$ and $c_{\mathrm{i}} \ll 1$, that is to say, dilute vapour mixtures. Equation (16) provides the reference level, which must now be corrected for the effect of an appreciable induced velocity. In equation (16) the 
transfer coefficient of mass is given by

$$
g_{m}=\frac{\rho \mathbb{D}}{\delta_{c}} .
$$

To derive the diffusional transport of mass from the mixture to the wall, equations (15) and (17) are applied to equation (6)

$$
\dot{m}=-g_{m} \ln \left(\frac{1-c_{\mathrm{b}}}{1-c_{\mathrm{i}}}\right) .
$$

This logarithmic expression for the diffusional mass flux is the original result of Stefan [5]. The film model correction factor is now introduced by comparing the expression for the transfer rate with induced velocity and that without. That is to say, on a comparison of equation (18) with equation (16), the classical film model correction factor is derived :

$$
\Theta_{\mathrm{c}}=\frac{-\phi_{c}}{\mathrm{e}^{-\phi_{c}}-1}
$$

with as diffusional dimensionless mass flux in equation (19)

$$
\phi_{c}=\frac{\dot{m}}{g_{m}}
$$

where $\dot{m}$ follows from equation (18).

\subsection{Heat transfer}

The heat transfer from the fluid to the wall is described by Fourier's law as

$$
q=\left.k \frac{\mathrm{d} t}{\mathrm{~d} y}\right|_{y=0} .
$$

For a negligible induced velocity the transferred heat through the film is simply given by

$$
q=h_{\mathrm{g}}\left(t_{\mathrm{b}}-t_{\mathrm{i}}\right)
$$

which serves as the reference level for the effect of the induced velocity on heat transfer. The heat transfer coefficient in equation (22) is defined as

$$
h_{\mathrm{g}}=\frac{k}{\delta_{t}} .
$$

The heat transfer from fluid to wall is obtained by combining equations (10), (18), (21) and (23)

$$
q=h_{\mathrm{g}}\left(t_{\mathrm{b}}-t_{\mathrm{i}}\right)\left[\frac{-\frac{\dot{m} c_{p, v}}{h_{\mathrm{g}}}}{\exp \left(-\frac{\dot{m} c_{p, v}}{h_{\mathrm{g}}}\right)-1}\right] .
$$

On a comparison of equation (24) with equation (22) the following film model correction factor is derived:

$$
\Theta_{\imath}=\frac{-\phi_{t}}{\mathrm{e}^{-\phi_{t}}-1}
$$

with as thermal dimensionless mass flux in equation (25)

$$
\phi_{t}=\frac{\dot{m} c_{p, \mathrm{v}}}{h_{\mathrm{g}}} .
$$

The thermal correction factor (25) is commonly referred to as the Ackermann correction factor.

\subsection{Momentum transfer}

The exerted shear stress by the fluid on the wall is governed by Newton's law as

$$
\tau=\left.\eta \frac{\mathrm{d} u}{\mathrm{~d} y}\right|_{y=0} .
$$

Without mass transfer the shear stress is described by

$$
\tau=\frac{1}{2} \rho f u_{\mathrm{b}}^{2}
$$

with friction coefficient defined as

$$
f=\frac{2 \eta}{\rho u_{\mathrm{b}} \delta_{u}} .
$$

This friction factor is usually called Fanning friction factor. The interfacial shear stress exerted by the fluid on the wall is determined with equations (14), (18), (27) and (29)

$$
\tau={ }_{2}^{1} \rho f u_{\mathrm{b}}^{2}\left[\frac{-\frac{2 \dot{m}}{\rho f u_{\mathrm{b}}}}{\exp \left(-\frac{2 \dot{m}}{\rho f u_{\mathrm{b}}}\right)-1}\right] .
$$

On a comparison of equation (30) with equation (28) the film model correction factor for momentum transfer is obtained

$$
\Theta_{u}=\frac{-\phi_{u}}{\mathrm{e}^{-\phi_{u}}-1}
$$

with as frictional dimensionless mass flux in equation (31)

$$
\phi_{u}=\frac{2 \dot{m}}{\rho f u_{\mathrm{b}}}
$$

The correction factor (31) for interfacial shear stress was first derived by Mickley et $a l$. [10].

For condensation problems, $c_{\mathrm{b}}>c_{\mathrm{i}}$ and thus $\dot{m}>0$, the correction factors (19), (25) and (31) are larger than unity. On the other hand, for wall evaporation, $c_{\mathrm{b}}<c_{\mathrm{j}}$ and $\dot{m}<0$, the correction factors are smaller than unity. For small mass transfer rates, $\dot{m} \simeq 0$ or $\left(c_{\mathrm{b}}-c_{\mathrm{i}}\right) /\left(1-c_{\mathrm{i}}\right) \simeq 0$, the correction factors tend asymptotically to unity. Or in other words, the induced velocity plays no role of importance and consequently, uncorrected heat transfer, mass transfer and friction predictions will suffice.

The diffusional mass flux $\dot{m}$ in equations (20), (26) and (32) is taken from equation (18). For injection or suction problems with an imposed mass flux, this mass flux can be substituted in these equations to determine the three film model correction factors. Thus, identical 
correction factors follow from the film model equations with a constant imposed mass flux in the film which, like the diffusionally induced mass flux, is independent of $y$; this can be verified by considering equations (3) and (6).

Mizushina et al. [14] among others, successfully employed the thermal correction factor in describing the heat transfer of a pure superheated vapour in the presence of a condensation mass flux. Surface injection and suction in tubes with porous walls have been the subject of numerous experiments and calculations. In the recent article of Wang and $\mathrm{Tu}$ [15] results of these efforts have been found in good agreement with the film model correction factors for friction and mass transfer. Summarizing, though the film model correction factors are here derived on the basis of a diffusional mass flux, they can be derived from and applied to imposed suction and injection as well. For this reason in what follows the terms 'suction' and 'injection' will be used to indicate situations involving respectively mass transfer to and from a wall, even if this mass transfer is due to condensation or evaporation.

\section{APPLICATION OF THE FILM MODEL TO CHANNEL FLOW}

In the previous section correction factors have been introduced to account for the effect of the induced velocity on mass and heat transfer and on shear stress. In this section the practical use and application of these factors in incompressible convective channel flow is demonstrated. The approach is based on the overall conservation laws of mass, energy and momentum and is applicable to any cross-sectional channel shape and geometry.

\subsection{Mass balance}

The gas mixture flows through the channel in the $x$-direction. Between the mixture and the wall of the channel there exists a transfer of mass, heat and momentum. The mean mixed values of vapour mass fraction and temperature in a cross-section (i.e. the values that would result after mixing of a crosssection), are denoted by $\bar{c}$ and $\bar{t}$, respectively. A differential mass balance for an element $\mathrm{d} x$, as shown schematically in Fig. 2, yields

$$
\frac{\mathrm{d}(\rho \bar{u})}{\mathrm{d} x}=-\frac{4}{D_{\mathrm{h}}} \dot{m}=-\frac{4}{D_{\mathrm{h}}} g_{m} \Theta_{c} \frac{\bar{c}-c_{\mathrm{i}}}{1-c_{\mathrm{i}}} .
$$

In this equation the hydraulic diameter $D_{\mathrm{h}}$ is defined as four times the cross-sectional area divided by the perimeter of the channel and $\bar{u}$ is the mixture's mean velocity. The mass transfer coefficient is given by equation (17), in which is substituted

$$
\delta_{c}=\frac{D_{\mathrm{h}}}{S h}
$$

where $S h$ represents the local convective flow Sher-

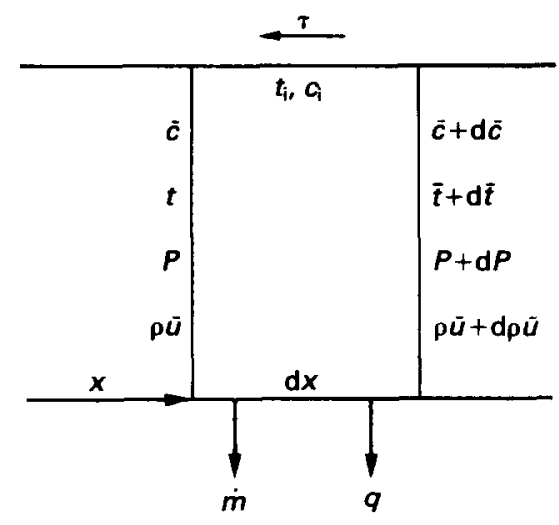

FIG. 2. The channel.

wood number for low mass transfer rates, pertaining to the considered channel geometry. The implicit assumption is thus made that $\delta_{c}$ is not itself a significant function of the mass transfer rates. Moreover, as the first-order approximation in the film model correction factors $c_{\mathrm{b}}$ (and $u_{\mathrm{b}}$ ) is replaced by $\bar{c}$ (and $\bar{u}$ ), and the film thickness $\delta_{c}$ is approximated by equation (34).

For a binary mixture, the change in mass flow through the channel is related to the vapour mass fraction by

$$
(\rho \bar{u})(x)(1-\bar{c}(x))=(\rho \bar{u})(x=0)(1-\bar{c}(x=0)) .
$$

Equation (33) then yields

$$
\frac{\mathrm{d} \bar{c}}{\mathrm{~d} x}=\frac{-4 g_{m}}{D_{\mathrm{h}}(\rho \bar{u})(x=0)} \Theta_{\mathrm{c}} \frac{\bar{c}-c_{\mathrm{i}}}{1-c_{\mathrm{i}}} \frac{(1-\bar{c})^{2}}{(1-\bar{c}(x=0))} .
$$

Equation (35) prescribes mathematically the mass conservation of the inert components entering and flowing through the channel. Equation (36), with application of equations (18)-(20), is rewritten as

$$
\begin{aligned}
\frac{\mathrm{d} \bar{c}}{\mathrm{~d} x}=\frac{4 g_{m}}{D_{\mathrm{h}}(\rho \bar{u})(x=0)} \ln \left(\frac{1-\bar{c}}{1-c_{\mathrm{i}}}\right) & \\
& \times \frac{(1-\bar{c})^{2}}{(1-\bar{c}(x=0))} .
\end{aligned}
$$

\subsection{Energy balance}

The change of the mean mixed bulk temperature $\bar{t}$ of the mixture flowing through the channel is obtained by employing an incremental energy balance, see Fig. 2

$$
\begin{aligned}
\frac{\mathrm{d} \bar{t}}{\mathrm{~d} x} \rho \bar{u}(x) \frac{D_{\mathrm{h}}}{4} c_{p}-\dot{m}\left(\bar{t}-t_{\mathrm{i}}\right) & c_{p, v} \\
= & -q=-h_{\mathrm{g}} \Theta_{i}\left(\bar{t}-t_{\mathrm{i}}\right) .
\end{aligned}
$$

Equation (38) is, with equations (26) and (35), rewritten for a binary mixture as 


$$
\begin{aligned}
\frac{\mathrm{d} \bar{t}}{\mathrm{~d} x}=\frac{-4 h_{\mathrm{g}}}{c_{p} D_{\mathrm{h}}(\rho \bar{u})(x=0)} & \left(\Theta_{i}-\phi_{i}\right) \\
& \times\left(\bar{t}-t_{\mathrm{i}}\right) \frac{(1-\bar{c})}{(1-\bar{c}(x=0))} .
\end{aligned}
$$

In equations (26), (38) and (39) $h_{\mathrm{g}}$ is defined by equation (23) with as film thickness applied:

$$
\delta_{t}=\frac{D_{\mathrm{h}}}{N u}
$$

where $N u$ is the local convective flow Nusselt number at low mass transfer rates belonging to the studied channel shape. With equation (25) it can be verified that $\Theta_{i}\left(\phi_{i}\right)-\phi_{i}$ is identical with $\Theta_{i}\left(-\phi_{i}\right)$. This implies that these identical functions are smaller than unity for suction and larger than unity for injection; $\Theta_{t}\left(\phi_{t}\right)$ and its reflection in the vertical axis $\Theta_{t}\left(-\phi_{t}\right)$ are depicted in Fig. 3. Suction thus enhances the heat transfer at the wall, while the temperature drop of the mixture nevertheless becomes smaller as mass is absorbed at the wall. This opposite conduction of heat flux and temperature alteration has already been noticed and discussed by Colburn and Drew [9] when applying the film model to heat and mass transfer in channel flow. Subsequent workers applied the film model to combined heat and diffusional mass transfer in condensers and evaporators and found in good agreement with practice, e.g. see the results of Webb and Sardesai [12] or the procedures recommended by V.D.I. [4].

\subsection{Momentum balance}

An expression for the pressure drop in a channel follows from a differential momentum balance on the material between the planes $x$ and $x+\mathrm{d} x$, see Fig. 2

$$
\frac{\mathrm{d} P}{\mathrm{~d} x}+\frac{\mathrm{d}\left(\rho \overline{u^{2}}\right)}{\mathrm{d} x}=-\tau \frac{4}{D_{\mathrm{h}}}=-\Theta_{u} \frac{1}{2} \rho \bar{u}^{2} f \frac{4}{D_{\mathrm{h}}}
$$

The second term on the left-hand side represents the vapour deceleration or acceleration owing to suction or injection, respectively. In equations (41) the coefficient $f$ is the local friction coefficient at low mass transfer rates pertaining to the considered channel

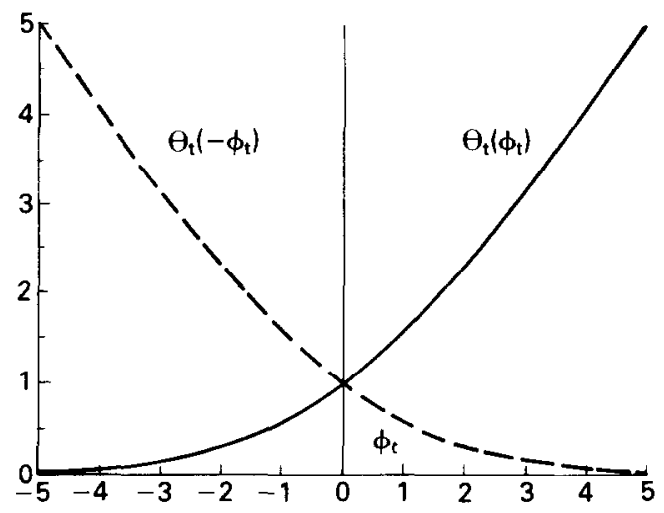

FIG. 3. Ackermann correction function and its reflection in the vertical axis. shape. Substituting equations (32) and (33) and rearranging equation (41) yields

$$
\frac{\mathrm{d} P}{\mathrm{~d} x}=-\frac{2 \rho f \bar{u}(x)^{2}}{D_{\mathrm{h}}}\left(\Theta_{u}-2 \frac{\overline{u^{2}}}{\bar{u}^{2}} \phi_{u}\right) .
$$

In deriving equation (42) the variation of the mixture's density and momentum flux coefficient (which is the ratio of mean square and square mean velocity) in the direction of $x$ have been considered as zero: within the accuracy of the present model this distinction is minor.

Result (42), the film model expression for the pressure drop, has-to the authors' knowledge-never been obtained before. It is therefore compared extensively in the following with results of experimental and theoretical studies of flow through closed channels with porous walls in the presence of imposed suction and injection. In the past considerable effort has been expended to this flow since it has been applied to transpiration cooling and boundary layer control, and is also found in membranes for production of uranium-235, artificial kidney dialysis and culturing of animal cells. In all studied papers it has been assumed that the laminar or turbulent porous channel flow is self-similar. The self-similarity is defined as a state of flow in which a local velocity distribution divided by the cross-sectional average velocity does not vary in the flow direction (i.e. invariant momentum flux coefficient), and it offers the advantage of simplifying the equations of continuity and motion considerably.

Fully developed laminar fluid flow between parallel plates and in circular tubes with surface injection and suction has been studied analytically by many investigators. For both cases the governing continuity and Navier-Stokes equations were reduced to a single, fourth-order, non-linear ordinary differential equation. This equation was initially solved using perturbation methods and subsequently using numerical integration.

A listing of all relevant papers on flow between parallel plates can be found in the notes by Terrill $[16,17]$, particular reference being made here to the contributions of Berman [18, 19] and Yuan [20]. The second-order approximation for $\left|\phi_{u}\right|<1 / 3$ of the differential pressure variation reads

$$
\frac{\mathrm{d} P}{\mathrm{~d} x}=-\frac{2 \rho f \bar{u}(x)^{2}}{D_{\mathrm{h}}}\left(1-\frac{81}{35} \phi_{u}+3 \frac{468}{35770} \phi_{u}^{2}\right)
$$

and the asymptotic approximation for $\left|\phi_{u}\right|>1 / 3$ is

$$
\begin{aligned}
\frac{\mathrm{d} P}{\mathrm{~d} x}=- & \frac{2 \rho f \bar{u}(x)^{2}}{D_{\mathrm{h}}}\left(\frac{2.049}{3}-\frac{\pi^{2}}{4} \phi_{u}\right) \quad\left(\phi_{u}<-1 / 3\right) \\
& \frac{\mathrm{d} P}{\mathrm{~d} x}=-\frac{2 \rho f \bar{u}(x)^{2}}{D_{\mathrm{h}}}\left(-\phi_{u}\right)\left(\frac{3 \phi_{u}}{3 \phi_{u}-1}\right)^{2} \\
& \times\left(1+\frac{6}{\left(3 \phi_{u}-1\right)^{2}}+\frac{53.5}{\left(3 \phi_{u}-1\right)^{3}}\right) \quad\left(\phi_{u}>1 / 3\right) .
\end{aligned}
$$




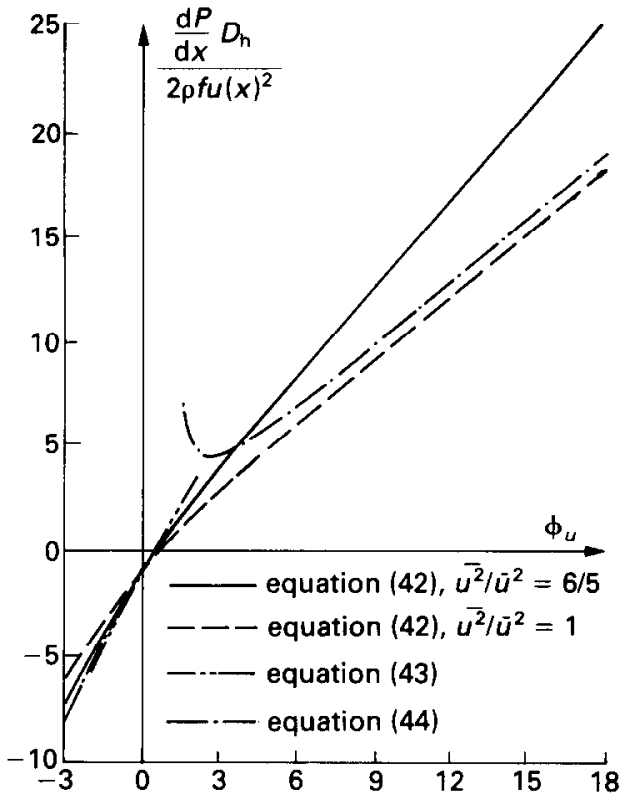

FIG. 4. Pressure drop of laminar flow between parallel plates in the presence of suction and injection

In Fig. 4 the dimensionless pressure gradient is depicted, according to equations (42)-(44), as a function of the dimensionless suction rate $\phi_{u}$. In equation (42) the momentum flux coefficient $6 / 5$ is substituted, derived from undisturbed Poiseuille flow, i.e. $\phi_{u}=0$, between parallel plates, see Table 1 .

Figure 4 shows the trend that the film model underpredicts the effect of large injection rates and overpredicts the effect of large suction rates on the pressure drop. This can be understood from the fact that the velocity profile in the centre of the channel steepens slightly and flattens substantially ('plug flow') for large injection and suction, respectively. Hence for large suction rates the momentum flux coefficient will tend to unity, while for injection the momentum flux coefficient will even be larger than the values listed in Table 1. To illustrate the pertinent influence of the momentum flux coefficient on the pressure drop predictions, equation (42) is also drawn in Fig. 4 with a momentum flux coefficient of unity substituted. For injection the prediction is worse, as expected, while for large suction rates the determined pressure drop is indeed in better agreement with the referred results.

Perturbation solutions of the governing equations

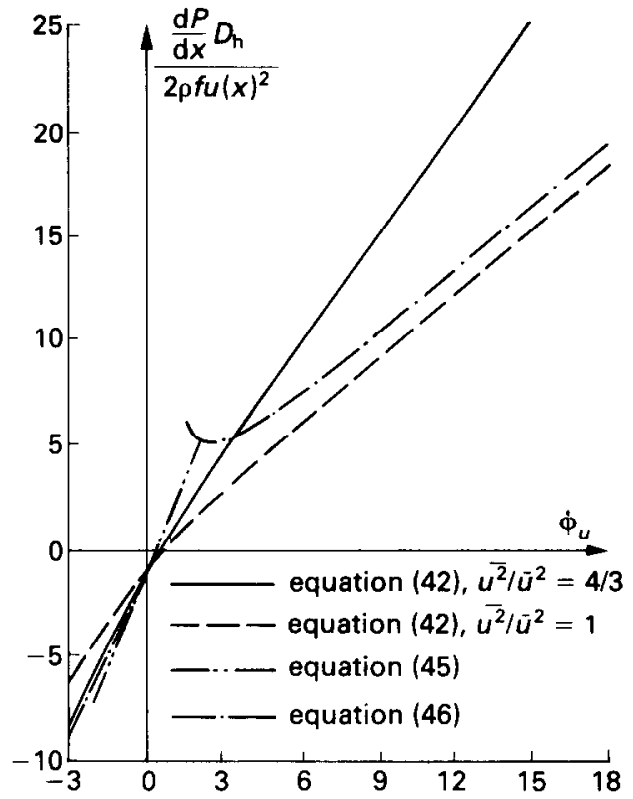

FIG. 5. Pressure drop of laminar flow in a circular tube in the presence of suction and injection.

of laminar flow through porous circular tubes for large and small $\left|\phi_{u}\right|$ have been derived by Yuan and Finkelstein [21] and Terrill and Thomas [22]. Some of these theoretical predictions have been confirmed experimentally by Bundy and Weissberg [23]. For $\left|\phi_{u}\right|<1 / 4$ as first-ordcr approximation for the pressure drop was obtained

$$
\frac{\mathrm{d} P}{\mathrm{~d} x}=-\frac{2 \rho f \bar{u}(x)^{2}}{D_{\mathrm{h}}}\left(1-3 \phi_{u}\right)
$$

and as approximation for $\left|\phi_{u}\right|>1 / 4$

$$
\begin{array}{r}
\frac{\mathrm{d} P}{\mathrm{~d} x}=-\frac{2 \rho f \bar{u}(x)^{2}}{D_{\mathrm{h}}}\left(1.3253-2.4674 \phi_{u}\right) \quad\left(\phi_{u}<-1 / 4\right) \\
\frac{\mathrm{d} P}{\mathrm{~d} x}=-\frac{2 \rho f \bar{u}(x)^{2}}{D_{\mathrm{h}}}\left(-\phi_{u}\right)\left(1+\frac{1}{\phi_{u}}+\frac{7}{4 \phi_{u}^{2}}+\frac{21}{4 \phi_{u}^{3}}\right) \\
\left(\phi_{u}>1 / 4\right) . \quad(46)
\end{array}
$$

In Fig. 5 equations (45), (46) and (42), with as momentum flux coefficients 1 and $4 / 3$ substituted, are drawn. This latter value is based on the parabolic velocity profile of Hagen-Poiseuille flow in a tube, in the absence of suction and injection, see Table 1. Figure

Table 1. Neutral $\left(\phi_{u}=0\right)$ friction coefficients and momentum flux coefficients ( $n$ denotes the turbulent power-law exponent)

\begin{tabular}{cccccc}
\hline & \multicolumn{2}{c}{ Laminar flow } & & \multicolumn{2}{c}{ Turbulent flow } \\
\cline { 2 - 3 } \cline { 5 - 6 } & Parallel plates & Circular tube & & Parallel plates & Circular tube \\
\hline $\bar{u}^{2} / \bar{u}^{2}$ & $6 / 5$ & $4 / 3$ & & $(1+n)^{2} /(2+n) n$ & $(1+n)^{2}(1+2 n)^{2} /$ \\
$f$ & $24 / R e$ & $16 / R e$ & & $0.079 / e^{0.25}$ & $\begin{array}{c}2 n^{2}(2+n)(2+2 n) \\
0.079 / R e^{0.25}\end{array}$ \\
\hline
\end{tabular}


5 indicates that the film model with a momentum flux coefficient of $4 / 3$ substituted is in reasonable agreement with the asymptotic results for small $\left|\phi_{u l}\right|$. In contrast to flow between parallel plates, the referred authors found that the profiles flatten both for injection and suction. Figure 5 confirms that the effect of a flatter profile is more pronounced for suction (likewise laminar flow between parallel plates); equation (42) with momentum flux coefficient unity substituted is indeed in better agreement.

The pressure drop of turbulent flow through circular tubes, in the presence of surface injection and suction, has been the subject of numerous experimental and theoretical works in the past. In Fig. 6 the line based on the injection experiments of Olson and Eckert [24] is depicted. The Reynolds number $R e$ ranged from 28000 up to 82000 . One of their findings was that the velocity field in the tube becomes fully developed within 12 tube diameters. The concept of self-similarity of the velocity field formed the basis of comprehensive suction computations performed by Kinney and Sparrow [25]. In Fig. 6 their result for $R e=50000$ is drawn. Mizushina et al. [26] derived an empirical relation for the pressure drop as a function of the suction rate. This relation is based on both suction and injection experiments, $R e$ ranging from 9000 to 102500 . The suction rate $-v(y=0) / \bar{u}$ range of their experiments was confined from -0.017 to 0.019 , see Fig. 6.

In this figure also equation (42) has been drawn with $4 f$ set equal to 0.023 and a momentum flux coefficient of 1 and 1.02. The value of $f$ is obtained from the intersection of all lines, depicted in Fig. 6, with the vertical axis, corresponding, to the neulral

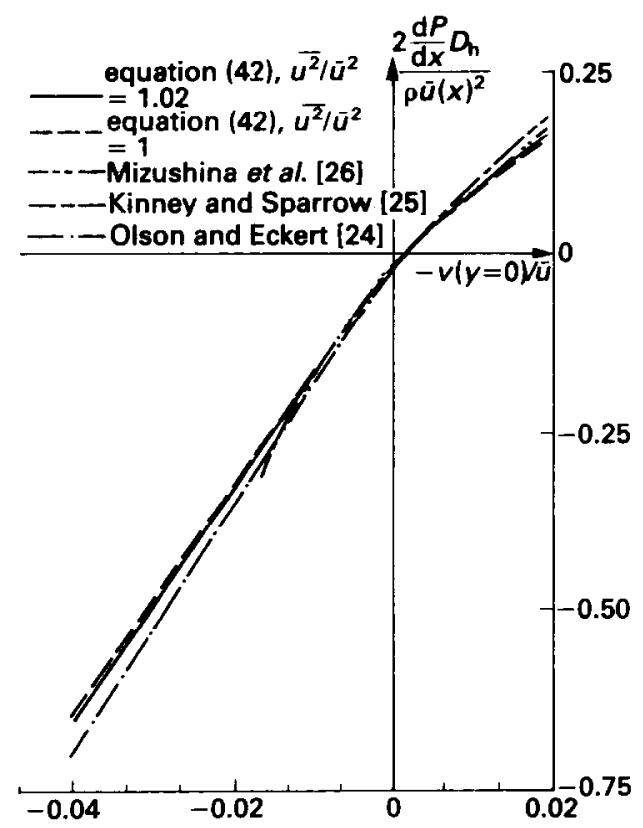

Fig. 6. Pressure drop of turbulent flow through a circular pipe in the presence of suction and injection. case of neither suction nor injection. This friction coefficient of turbulent flow through a circular tube corresponds, according to Blasius' equation, see Table 1 , with a Reynolds number of about 36000 , which is indeed within the range investigated by the various authors. The momentum flux coefficient listed in Table 1 follows from the developed turbulent flow power-law velocity profile in the tube, see Ward-Smith [27]. With power-law exponent $n=7$ substituted, this value of $n$ pertains to the aforesaid Reynolds number, the mentioned momentum flux coefficient 1.02 is obtained.

Figure 6 indicates the good agreement between the original and compact equation (42), and all results of afore-mentioned investigators, in particular when the momentum flux coefficient of 1.02 is applied. The agreement remains within $10 \%$ for the largest suction rate, and within $8 \%$ for the largest injection rate. These large values of $|v(y=0) / \bar{u}|$ are typical of tubes with porous walls; diffusional 'injection' or 'suction' rates in evaporators or condensers are usually smaller.

In Figs. 4-6 the enhancement of the pressure drop is illustrated as the injection rate rises, due to the amount of added gas to be accelerated. One can also see the sign change of the pressure drop for sufficiently large suction rates, caused by the momentum decrease of flowing fluid. From equations (31) and (42) the non-dimensional mass flux pertaining to the zero press ure drop situation is derived analytically as

$$
\phi_{u}=\ln \left(\frac{2 \overline{u^{2}} / \bar{u}^{2}}{2 \overline{u^{2}} / \bar{u}^{2}-1}\right)
$$

The strength of equations (42) and (47) lies in the fact that they are not limited to one channel shape or one Reynolds number. To apply these simple and compact equations one only needs to know, for a given channel shape, the uncorrected friction factor as a function of the Reynolds number, and the ratio of mean square and square mean velocity. This ratio is in general close to unity for turbulent flow, but a better prediction is obtained when the momentum flux coefficient is actually assessed and applied. For laminar flow the momentum flux coefficient is evidently unequal to unity, but can readily be obtained from a consideration of the neutral velocity profile in the channel.

\section{RELATION BETWEEN $c$ AND $t$ IN THE FILM AND THE PATH OF $\bar{c}$ AND $\bar{t}$}

In previous sections film model correction factors have been derived and applied to the case of closed channel flow. In this section the relation of vapour mass fraction and temperature in the film with respect to the saturation line is discussed, in particular the possible crossing of this line. Furthermore, attention is focused on the path of the mean mixed values $\bar{t}$ and $\bar{c}$ of a binary mixture flowing through a channel, and the entering of these properties into the super- 
saturated region. Special attention is paid to a binary mixture for which

$$
N u=S h
$$

or

$$
\frac{\delta_{c}}{\delta_{t}}=\frac{N u}{S h}=1
$$

see equations (34) and (40), corresponding to equal temperature and diffusion film thicknesses. Both equalities apply to any heat and mass transfer problem, either convective or non-convective, cithcr laminar or turbulent, for a Lewis number $L e=1$. They also apply to fully developed laminar flow with a Lewis number $L e \neq 1$.

To express the vapour mass fraction as a function of the temperature in the film, the coordinate $y / \delta_{c}$ is eliminated from equations (6) and (10), resulting in evaporation, while $G(t)$ is concave for $L e_{\mathrm{v}}>1$ with condensation or evaporation. For $L e_{\mathrm{v}}=1, G(t)$ is a straight line, both for evaporation and condensation. In Fig. 7 the possible shapes of $G(t)$ for equal film thicknesses (corresponding to equality (49)) are depicted. In fact $y$ acts as a parameter of each curve depicted in this figure. In the figure the saturation line $F(t)$ of the mixture concerned is also drawn.

It can be seen that a part of the film is supersaturated, even when $\left(t_{\mathrm{b}}, c_{\mathrm{b}}\right)$ is situated in the superheated region. The part of the film that is positioned in the supersaturated region, is thermodynamically in an unstable state. As a result condensation takes place and fog is created : by homogeneous nucleation and heterogeneous condensation on foreign particles, see Steinmeyer [28]. Where fog is formed, the basic diffusion and energy equations are locally altered.

$\delta_{c}<\delta_{t}\left[\begin{array}{ll}c=G(t)=1+\left(c_{\mathrm{i}}-1\right)\left(\frac{t-t_{\mathrm{i}}}{t_{\mathrm{b}}-t_{\mathrm{i}}}\left[\exp \left\{\frac{\delta_{t}}{L e_{\mathrm{v}} \delta_{c}} \ln \left(\frac{1-c_{\mathrm{b}}}{1-c_{\mathrm{i}}}\right)\right\}-1\right]+1\right)^{L_{\mathrm{v}}} & \left(t_{\mathrm{i}} \leqslant t \leqslant t\left(y=\delta_{c}\right)\right) \\ c=c_{\mathrm{b}} & \left(t\left(y=\delta_{c}\right) \leqslant t \leqslant t_{\mathrm{b}}\right)\end{array}\right.$

$\delta_{t}=\delta_{t}: c=G(t)=1+\left(c_{\mathrm{i}}-1\right)\left(\frac{t-t_{\mathrm{i}}}{t_{\mathrm{b}}-t_{\mathrm{i}}}\left[\exp \left\{\frac{1}{L e_{\mathrm{v}}} \ln \left[\frac{1-c_{\mathrm{h}}}{1-c_{\mathrm{i}}}\right]\right\}-1\right]+1\right)^{L e_{\mathrm{v}}} \quad\left(t_{\mathrm{i}} \leqslant t \leqslant t_{\mathrm{b}}\right)$

$\delta_{c}>\delta_{t}\left[\begin{array}{l}c=G(t)=1+\left(c_{\mathrm{i}}-1\right)\left(\frac{t-t_{\mathrm{i}}}{t_{\mathrm{b}}-t_{\mathrm{i}}}\left[\exp \left\{\frac{\delta_{t}}{L e_{\mathrm{v}} \delta_{c}} \ln \left(\frac{1-c_{\mathrm{b}}}{1-c_{\mathrm{i}}}\right)\right\}-1\right]+1\right)^{L e_{\mathrm{v}}} \quad\left(t_{\mathrm{i}} \leqslant t \leqslant t_{\mathrm{b}}\right) . \\ c \text { is not a function of } t \text { for } \delta_{t}<y \leqslant \delta_{c}\end{array}\right.$.

Equation (50) relates $c$ and $t$ in the film. Both for condensation (that is to say $c_{\mathrm{b}}>c_{\mathrm{i}}$ ) and for evaporation $\left(c_{\mathrm{b}}<c_{\mathrm{i}}\right), G(t)$ proves to be a monotonically increasing function of $t$. This property follows from the first derivative of $G(t)$ with respect to $t$. Differentiating $G(t)$ twice with respect to $t$ makes it clearer that $G(t)$ is convex for $L e_{v}<1$ with condensation or
In order to study the behaviour of the bulk, or mean mixed temperature, $\bar{t}$, and vapour concentration, $\bar{c}$, of a binary mixture flowing through a channel, the coordinate $x$ is eliminated from equations (37) and (39). Substituting equations (17), (18), (23), (25), (26), (34) and (40), assuming uniform interface conditions, separating the variables $\bar{t}$ and $\bar{c}$, and integrating yields :

$\bar{c}=\bar{G}(\bar{t})=1+\left(c_{\mathrm{i}}-1\right)\left(\left[\frac{\bar{t}-t_{\mathrm{i}}}{\bar{t}(x=0)-t_{\mathrm{i}}}\right]^{[S h /(N u L e)]}\left[\exp \left\{\frac{S h}{L e_{\mathrm{v}} N u} \ln \left[\frac{1-\bar{c}(x=0)}{1-c_{\mathrm{i}}}\right]\right\}-1\right]+1\right)^{\left[\left(L e_{\mathrm{v}} N u\right) / S h\right]}$

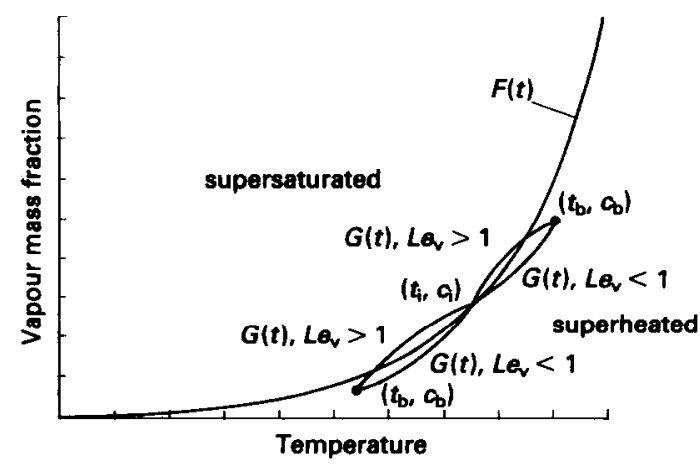

FIG. 7. Behaviour of $G(t), \delta_{t}=\delta_{c}$. where the values of $\bar{c}$ and $\bar{t}$ at an arbitrarily chosen location, $x=0$ (for instance the entrance of a channel), have been applied to determine the integration constant.

One can readily see that to $L e=1$, in view of equality (49), applies

$$
\bar{G}(\bar{l})=G(t) .
$$

This result is very interesting because for $L e=1$ the binary mixture's mean mixed temperature and vapour mass fraction $(\bar{t}, \bar{c})$ evidently 'walk', while the mixture flows through the channel, along $G(t)$ towards $\left(t_{i}, c_{i}\right)$, see Fig. 7. In other words, the curve $G(t)$ then acts as 
streamline for $(\bar{t}, \bar{c})$, independent of $L e_{\mathrm{v}}$, although this curve is originally derived from the temperature and vapour concentration relationship in the film. For $L e \neq 1$, however, it can be seen that the mixture follows $\bar{G}(\bar{t})$, but not $G(t)$.

Figure 7 also indicates that under certain circumstances the mean mixed properties may enter the supersaturated area, which will result in a supersaturated mixture when the flow through the channel in a cross-section is mixed. Colburn and Drew [9] already remarked that a mixture's bulk temperature and vapour fraction in a condenser may cross the saturation line and enter the supersaturated region. On the other hand, if the curvature of $G(t)$ is sharp enough $\left(L e_{\mathrm{v}}<1\right)$, it is possible that the $c-t$ relation in the film, as well as the path of the mean mixed values, remains in the superheated region, even if the mixture enters the channel saturated. It is interesting to notice that the bulk can be superheated or saturated, while $G(t)$ is situated in the supersaturated region. It is also possible that the bulk properties move to enter the supersaturated region, while $G(t)$ is localed in the superheated region. Hence it is important to distinguish two independent kinds of supersaturation and fog formation, namely:

- fog formation in the film,

- fog formation in the bulk, owing to the entering of the bulk properties into the supersaturated region.

In the former discussions $L e$ and $L e_{\mathrm{v}}$ have been treated as independent variables. However, it should be realized that $L e$ and $L e_{v}$ become identical when the vapour mass fraction tends to unity. Consequently, for large vapour fractions $L e_{\mathrm{v}} \neq 1$ also implies $L e \neq 1$.

\section{CONCLUDING REMARKS}

As the film model plays an important role in the practical description of heat and mass transfer processes, this model has been discussed in some detail in this paper. First, the three classical film model correction factors for energy, mass and momentum transfer have been derived for a diffusion induced velocity in a binary mixture. They can however be generalized to situations involving suction and injection. Moreover, in the past the results have also been successfully applied to multicomponent diffusion problems.

Subsequently, the film model correction factors have been applied to closed channel flow and universal expressions derived for the mean mixed vapour mass fraction, temperature, and pressure variation along the channel. The latter appears to be a new equation, and has been found in good functional accord with various non-diffusional suction and injection results of previous workers. The momentum flux coefficient (ratio of mean square velocity and square mean velocity) in a channel proved to be an important parameter in predicting the laminar flow pressure vari- ation in the presence of suction and injection. As the turbulent flow velocity profile approximates plug flow, this coefficient is therefore close to unity.

The local vapour mass fraction in the film has been expressed as a function $G(t)$ of the local temperature. The relation between $G(t)$ and the onset of fog formation in the film has been discussed. In a following paper $G(t)$ will fruitfully be employed to investigate the possible fog formation in a film. Furthermore, it has been demonstrated that the mean mixed vapour fraction $\bar{c}$ and temperature $\bar{t}$ of a binary mixture follow the relation $G(t)$ for $L e=1$, while flowing through a closed channel. Considering the path of $\bar{t}$ and $\bar{c}$ (represented by $\bar{G}(\bar{t})$ ) with respect to the saturation line, it has been seen that these properties may enter the supersaturated region (implying formation of fog in the bulk) or, on the other hand, remain in the superheated region.

Acknowledgement-The authors want to thank the management of Akzo Research Laboratories Arnhem for their permission to publish this paper and Messrs H. P. Korstanje and $G$. Vegt for their support of this work.

\section{REFERENCES}

1. R. B. Bird, W. E. Stewart and E. N. Lightfoot, Transport Phenomena. Wiley, New York (1960).

2. T. K. Sherwood, R. L. Pigford and C. R. Wilke, Mass Transfer. McGraw-Hill, New York (1975).

3. R. H. Perry and D. W. Green, Perry's Chemical Engineers' Handbook, 6th Edn. McGraw-Hill, New York (1984).

4. V.D.I., V.D.I.-Wärmeatlas, 5. Aufl. V.D.I. Verlag $\mathrm{GmbH}$ (1988) (in German).

5. J. Stefan, Versuche über die Verdampfung, Sitzgs.-Ber. pertur- und Partialdruckdifferenzen VDI Forsch Hft. 382 (1937) (in German).

6. E. R. Gilliland and T. K. Sherwood, Diffusion of vapors into air streams, Ind. Engng Chem. 26, 516-523 (1934).

7. A. P. Colburn and O. A. Hougen, Design of cooler condensers for mixtures of vapors with noncondensing gases, Ind. Engng Chem. 26, 1178-1182 (1934).

8. G. Ackermann, Wärmeübertragung und molekulare Stofübertragung in gleichen Feld bei groszen Temperatur- und Partialdruckdifferenzen, VDI Forsch $H \mathrm{ft}$. 382 (1937) (in German).

9. A. P. Colburn and T. B. Drew, The condensation of mixed vapours, Trans. A.I.Ch.E. 33, 197-212 (1937).

10. H. S. Mickley, R. C. Ross, A. I. Squyers and W. F. Stewart, Heat, mass, and momentum transfer for flow over a flat plate with blowing or suction, NACA Tech. Note 3208 (1954).

11. H. L. Toor, Diffusion in three-component gas mixtures, A.I.Ch.E. Jl 3, 198-207 (1957).

12. D. R. Webb and R. G. Sardesai, Verification of multicomponent mass transfer models for condensation inside a vertical tube, Int. J. Multiphase Flow 7, 507-520 (1981).

13. H. J. Merk, Stofoverdracht in laminaire grenslagen door gedwongen convectie, D.Sc. Thesis, Technische Universiteit Delft (1957) (in Dutch).

14. T. Mizushina, R. Ito, S. Yamashita and H. Kamimura, Film condensation of a pure superheated vapor inside a vertical tube, Int. Chem. Engng 18, 672-679 (1978).

15. C. Y. Wang and C. J. Tu, Effects of non-condensable gas on laminar film condensation in a vertical tube, Int. J. Heat Mass Transfer 31, 2339-2345 (1988).

16. R. M. Terrill, Laminar flow in a uniformly porous channel, Aeronaut. $Q$. 15, 299-310 (1964). 
17. R. M. Terrill, Laminar flow in a uniformly porous channel with large injection, Aeronaut. Q. 16, 323-332 (1965).

18. A. S. Berman, Laminar flow in channels with porous walls, J. Appl. Phys. 24, 1232-1235 (1953).

19. A. S. Berman, Concerning laminar flow in channels with porous walls, J. Appl. Phys. 27, 1557-1558 (1956).

20. S. W. Yuan, Further investigation of laminar flow in channels with porous walls, J. Appl. Phys. 27, 267-269 (1956).

21. S. W. Yuan and A. B. Finkelstein, Laminar pipe flow with injection and suction through a porous wall, Trans. Am. Soc. Mech. Engrs 78, $719-724$ (1956).

22. R. M. Terrill and P. W. Thomas, On laminar flow through a uniformly porous pipe, Appl. Scient. Res. 21, 37-67 (1969).

23. R. D. Bundy and H. L. Weissberg, Experimental study of fully developed laminar flow in a porous pipe with wall injection, Physics Fluids 13, 2613-2615 (1970).

24. R. B. Olson and E. R. G. Eckert, Experimental studies of turbulent flow in a porous circular tube with uniform fluid injection through the tube wall, J. Appl. Mech. 33, 7-17 (1966).

25. R. B. Kinney and E. M. Sparrow, Turbulent flow, heat transfer, and mass transfer in a tube with surface suction, J. Heat Transfer 92, 117-125 (1970).

26. T. Mizushina, F. Ogino and S. Takeshita, Eddy diffusivity in a turbulent pipe flow with uniform fluid injection and suction through a wall, J. Chem. Engng Japan 8 , 217-223 (1975).

27. A. J. Ward-Smith, Internal Fluid Flow. Clarendon Press, Oxford (1980).

28. D. E. Steinmeyer, Fog formation in partial condensers, Chem. Engng Progress 68, 64-68 (1972).

\title{
DES MODELES DE FILM POUR LES PHENOMENES DE TRANSPORT AVEC FORMATION DE BROUILLARD
}

\begin{abstract}
Résumé-On réexamine et élargit le modèle classique du film (ou théorie du film). Tout d'abord par une analyse serrée, les équations de la diffusion, de l'énergie et de la quantité de mouvement d'un film stagnant sont établies et résolues. Ensuite, les facteurs de correction bien connus sont obtenus pour l'effet de succion/injection sur le transfert de masse, de chaleur et de quantité de mouvement. Puis le modèle de film est appliqué à l'écoulement en conduite. Cette application donne une nouvelle expression pour la perte de pression qui est comparée avec des résultats expérimentaux et théoriques de chercheurs antérieurs et on obtient un bon accord. La formation de brouillard dans un mélange binaire, à la fois dans le film et/ou le coeur est expliquée graphiquement au moyen de la relation entre température et fraction massique de vapeur et de la ligne de saturation de la vapeur.
\end{abstract}

\section{FILMMODELLE FÜR TRANSPORTVORGÄNGE MIT NEBELBILDUNG : DAS KLASSISCHE FILMMODELL}

\begin{abstract}
Zusammenfassung - In der vorliegenden Analyse wird eine Zusammenfassung und eine Erweiterung des klassischen Filmmodells (oder Filmtheorie) gegeben. Zunächst werden auf der Grundlage einer eingehenden Analyse die Grundgleichungen für Diffusion, Energie- und Impulstransport in einem ruhenden Film formuliert und gelöst. Weiter werden die bekannten Korrekturfaktoren für den Einfluß einer Absaugung/Einspritzung auf den Stoff-, Wärme- und Impulstransport formuliert. Im nächsten Schritt wird mit Hilfe globaler Massen-, Energie-und Impulsbilanzen das Filmmodell auf eine Kanalströmung angewandt. Dabei ergibt sich ein neuer Ausdruck für den Druckabfall, der ausführlich mit experimentellen und theoretischen Ergebnissen früherer Untersuchungen verglichen wird. Die Übereinstimmung ist gut. Der Beginn einer Nebelbildung in einem binären Gemisch, sowohl im Film als auch im Kern der Strömung, wird auf grafische Weise mit Hilfe einer Beziehung zwischen Temperatur und Dampfmassenanteil sowie der Taulinie erklärt.
\end{abstract}

\section{ПЛЕНОЧНЫЕ МОДЕЛИ ЯВЛЕНИЙ ПЕРЕНОСА С ТУМАНООБРАЗОВАНИЕМ: КЛАССИЧЕСКАЯ ПЛЕНОЧНАЯ МОДЕЛЬ}

\begin{abstract}
Аннотация-Проведен анализ и обобщение классической пленочной модели (или пленочной теории). Вначале на основе детального анализа выводятся и решаются определяющие уравнения диффузии, энергии и импульса для неподвижной пленки. Затем выводятся хорошо известные поправочные коэффициенты для учета влияния отсоса/вдува на перенос массы, тепла и импульса. А затем с использованием общего баланса массы, энергии и импульса пленочная модель применяется к течению в канале. В результате получено выражение для перепада давления, расчеты по которому хорошо согласуются с экспериментальными и теоретическими результатами, полученными ранее другими исследователями. Начало туманообразования в бинарной смеси как в пленке, так и/или в объеме жидкости, иллюстрируется графически с помощью зависимости между температурой и паросодержанием, а также линии насыщения пара.
\end{abstract}




\section{ERRATUM}

H. J. H. Brouwers and A. K. Chesters, Film models for transport phenomena with fog formation : the classical film model, Int. J. Heat Mass Transfer 35, 1-11 (1992).

Formula (2) on p. 3 should read

$$
\rho v \frac{\mathrm{d} c}{\mathrm{~d} y}=\rho \mathbb{D} \frac{\mathrm{d}^{2} c}{\mathrm{~d} y^{2}}
$$

Reference [5] on p. 10 should read

5. J. Stefan, Versuche über die Verdampfung, Sitzgs.-Ber. Akad. Wiss. Wien (2) 68, 385-423 (1873) (in German). 